\title{
DIFERENÇAS DE EFICIÊNCIA ENTRE ENSINO PÚBLICO E PRIVADO NO BRASIL*
}

\author{
Breno Sampaio \\ Juliana Guimarães ${ }^{a}$
}

\section{RESUMO}

O ensino básico do Brasil vem sendo bastante questionado quanto a sua qualidade e eficiência. Avaliações realizadas pelo INEP mostram que aproximadamente 5\% dos alunos apresentam desempenho classificado em "adequado". Ainda ao longo dos últimos anos, esse desempenho vem decaindo devido exclusivamente ao desempenho dos alunos de escolas públicas. Motivado pela diferença entre as duas redes de ensino no Brasil, este artigo analisa a eficiência das escolas públicas e privadas por meio da metodologia desenvolvida por Thanassoulis (1999) e depois estendida por Portela e Thanassoulis (2001). Portela e Thanassoulis (2001) decompõem a eficiência geral em dois componentes distintos: um componente atribuído à instituição de ensino que o estudante frequentou e outro componente atribuído à eficiência somente do estudante. Os resultados obtidos mostram que há grandes diferenças de eficiência entre os colégios privados e públicos. Os colégios privados obtiveram eficiência máxima e os colégios públicos obtiveram eficiência de 0,901 , com destaque para os públicos federais que ficaram com 0,910 , enquanto os públicos estaduais obtiveram 0,879 . Os colégios foram então analisados quanto à equidade do ensino para diferentes níveis de conhecimento dos alunos. Isso mostrou que o ensino público federal apresentou eficiência tão boa quanto o ensino privado para os melhores alunos. Já para o ensino público estadual, os melhores alunos são mais prejudicados que os alunos intermediários, cuja eficiência do ensino fica pouco acima da eficiência média.

Palavras-chave: análise de eficiência, ensino público e privado, Brasil.

\begin{abstract}
Recently, quality and efficiency of elementary education in Brazil has been questioned. Evaluations conducted by INEP showed that only $5 \%$ of the students present a performance that can be classified as adequate. Even this low performance has been decreasing mainly due to the lower performance of public school students. Given the differences on public and private schools performance we decided to analyze the comparative efficiency of public and private schools using a methodology developed by Thanassoulis (1999) and further extended by Portela and Thanassoulis (2001). The former decomposes efficiency into two components: one attributed to the school and the other exclusively to the student. Results show large differences in efficiency between public and private schools. Private schools obtained maximum efficiency score while public ones reached only 0,901 . Moreover, federal public schools reached a score of 0,910 and state schools 0,879 . Schools were further analyzed with respect to the equity performance considering the different performance obtained by each student. This result showed that there is no difference between federal public and private schools. With respect to state schools, they showed relatively lower efficiency for the best students compared to average students.
\end{abstract}

Keywords: efficiency analysis, public and private schools, Brazil.

JEL classification: I21, I28, C14.

* Os autores agradecem sugestões e comentários de Yony Sampaio, Tiago Cavalcanti e Andrea Sales Soares de Azevedo Melo, assim como de dois pareceristas anônimos.

$\S$ Department of Economics, University of Illinois at Urbana-Champaign. Endereço para contato: 2005 S Orchard St, Apt C, Urbana, Illinois, 61801, USA. E-mail: sampaio2@illinois.edu.

a. Faculty of Economics, University of Cambridge. Endereço para contato: Faculty of Economics, University of Cambridge, Sidgwick Avenue, Cambridge, CB3 9DD, UK. E-mail: jgc29@cam.ac.uk.

Recebido em novembro de 2007. Aceito para publicação em setembro de 2008. 


\section{INTRODUÇÃO}

A importância da acumulação de capital humano vem sendo destacada por diversos autores desde Arrow (1962), Uzawa (1965), Lucas (1988) e Becker, Murphy e Tamura (1990), como aspecto crucial para o desenvolvimento econômico de um país. Segundo estimativas de Barros, Henriques e Mendonça (2000) para o Brasil, a expansão da educação influencia significativamente na redução do crescimento populacional, na queda da mortalidade infantil e no aumento da expectativa de vida. Neste sentido, a importância de um sistema educacional de qualidade e eficiente, que realmente possibilite um adequado aprendizado à população, é inquestionável.

Em avaliação internacional de desempenho de estudantes, realizada pela OCDE e denominada PISA $2000^{1}$ (Programme for International Student Assessment), o Brasil ocupou o último lugar em termos de desempenho médio em todas as provas realizadas (leitura, matemática e ciências). ${ }^{2} \mathrm{O}$ desempenho do Brasil foi ainda bastante inferior ao desempenho do México, país que, entre os analisados na pesquisa, tem características socioeconômicas mais próximas do Brasil. Diversas justificativas para o mau desempenho dos alunos brasileiros foram levantadas em relatório elaborado pelo INEP (2004) como: o nível socioeconômico do Brasil ser inferior aos demais países analisados, a desigualdade socioeconômica (medida pelo índice de Gini) ser mais aguda, a parcela de alunos com atraso escolar ser maior, entre outros. Porém, Waltenberg (2005), que analisou o desempenho brasileiro em relação ao desempenho mexicano, levando em conta os fatores levantados, conclui que o desempenho médio dos alunos brasileiros foi ainda inferior ao desempenho médio dos alunos mexicanos.

Para o Brasil, estudo divulgado pelo INEP (2002), que avalia o desempenho de estudantes do ensino médio por meio de indicadores disponibilizados pelo SAEB - Sistema Nacional de Avaliação da Educação Básica, $42 \%$ dos alunos foram qualificados em estado "muito crítico" e "crítico" no desenvolvimento de habilidades e competências em língua portuguesa. Os qualificados em "adequados" somam apenas 5\%. Ao traçar o perfil dos estudantes qualificados com desempenho muito crítico, $76 \%$ estão matriculados no ensino noturno, $48 \%$ conciliam trabalho e estudo, $84 \%$ estão acima da idade considerada ideal e, mais importante, $96 \%$ estudam em escolas públicas. Para o desempenho dos estudantes em língua portuguesa, o setor privado superou o setor público em 50 pontos. Para matemática, a diferença foi ainda maior, chegando a 81 pontos na região Sudeste.

Esta situação, já bastante delicada, é ainda agravada quando se faz a análise da evolução desses índices para anos anteriores da pesquisa. Desde 1995, o desempenho médio dos estudantes vem apresentando queda de $10 \%$ ao ano. Essa queda é dada exclusivamente pela queda de desempenho dos estudantes de escolas públicas, visto que o desempenho dos estudantes das escolas privadas apresentou aumento de 2,3 pontos para o período.

1 A PISA 2000 foi organizada com o objetivo de avaliar o nível de competências cognitivas de alunos de 32 países, dos quais 28 são membros da OCDE e quatro são convidados: Brasil, Letônia, Liechtenstein e Federação Russa.

2 Nas avaliações mais recentes do PISA (2003, 2006), os resultados obtidos pelo Brasil não foram diferentes. Por exemplo, no PISA 2006, o Brasil ocupou a $54^{a}$ posição entre 57 países analisados e obteve o pior desempenho entre os países da América Latina. 
A grande diferença de desempenho entre estudantes de escolas públicas e privadas levantam questões sobre suas causas e qual a magnitude dos fatores responsáveis. Ou seja, dadas as condições sociodemográficas e cognitivas de um estudante, qual seria a diferença de conhecimento adquirido se este estivesse matriculado no ensino público ou privado. Dito de outra forma, qual seria o real impacto da eficiência do estabelecimento de ensino no aprendizado de seus estudantes? E qual a diferença desse impacto entre as escolas públicas e privadas?

Diversos estudos analisam a eficiência de instituições de ensino, utilizando métodos como análise de regressão, modelos lineares hierárquicos ou multiníveis e análise envoltória de dados (DEA). Na análise de regressão, a eficiência da instituição de ensino é avaliada em função de variáveis agregadas para a instituição, o que, segundo Goldstein (1997), pode levar a conclusões equivocadas, pois não permite variações de desempenho entre os estudantes de uma mesma instituição, dado que esta variação está escondida na média. A análise de modelos lineares hierárquicos não utiliza dados agregados e consta da estimação de uma equação para cada instituição em função de dados em nível de aluno. Os coeficientes são então comparados, chegando a conclusões referentes à eficiência. Barbosa e Fernandes (2001) aplicaram essa metodologia para analisar diferenças entre escolas brasileiras e seus impactos no desempenho de estudantes. Os autores chegam à conclusão que fatores como motivação dos alunos, condições físicas da escola e atributos associados ao professor afetam significativamente a proficiência em matemática dos alunos de $4^{\mathrm{a}}$ série do ensino fundamental. Com relação à análise envoltória de dados, é um método não paramétrico utilizado para estimar coeficientes de eficiência de unidades tomadoras, como, por exemplo, instituições de ensino, bancos, sistemas de transporte público ou até mesmo alunos. Há diversas aplicações desta metodologia na literatura internacional para avaliação de eficiência de instituições de ensino superior (JESSON et al., 1987; JOHNES; JOHNES, 1993; JOHNES et al., 1993; GLASS et al., 1995). Johnes (2006) fez comparação entre resultados de eficiência de instituições de ensino obtidos por modelos lineares hierárquicos e análise envoltória de dados e chegou à conclusão que as eficiências derivadas dos dois modelos não são fortemente correlacionadas. As análises paramétricas permitem a obtenção da eficiência global e lidam melhor com erros de medida, enquanto a análise não paramétrica está limitada à amostra e é mais sensível a erros de medida. Na análise das instituições de ensino básico, a decomposição da eficiência é facilitada pelo uso de modelos DEA dada a grande simplicidade de estimação dos coeficientes.

Para o Brasil, a análise de eficiência tem também se concentrado bastante na avaliação de instituições de ensino superior por meio da análise envoltória de dados. Os trabalhos pioneiros dessa aplicação são Lopes, Lapa e Lanzer (1995-a, 1995-b,1996), Lapa, Lopes e Lanzer (1995) e Cury (1995). Podem-se encontrar ainda outras aplicações em Marinho et al. (1997), Nunes (1998), Amaral (1999), Paredes (1999) e Belloni (2000).

O objetivo principal deste trabalho é analisar a eficiência de instituições de ensino básico por meio da metodologia desenvolvida primeiramente por Thanassoulis (1999) e depois estendida por Portela e Thanassoulis (2001). Este método permite que se decomponha a eficiência obtida para cada aluno, dados seus insumos e produtos, em dois componentes distintos: um atribuído à instituição de ensino que o estudante frequentou e outro atribuído à eficiência somente do estudante. Obtidas as eficiências das instituições, já descontadas pelas eficiências dos 
estudantes, iremos comparar as instituições de ensino de forma a obter a diferença de eficiência do ensino público e privado.

Após esta seção de introdução, a próxima seção destaca alguns determinantes de desempenho escolar. A terceira seção inicia descrevendo o método da análise envoltória de dados (DEA) e, em seguida, apresenta graficamente o método utilizado para decomposição da eficiência. A quarta seção consta da aplicação empírica feita aos estudantes da Região Metropolitana do Recife - RMR-, que terminaram o ensino médio em 2005. Na última seção, são expostas as conclusões obtidas.

\section{ALGUNS DETERMINANTES DE DESEMPENHO ESCOLAR}

As características pessoais do indivíduo, a qualidade e a eficiência do estabelecimento de ensino e o background familiar influenciam o rendimento escolar dos estudantes.

Algumas das características dos indivíduos já foram bastante estudadas. Power et al. (1987) constataram que indivíduos do sexo feminino, que possuem desempenho semelhante ao do sexo masculino no ensino médio, têm, em geral, desempenho superior na universidade. Resultados semelhantes também foram obtidos por Birch e Miller (2006), Ma e Koenker (2005), Win e Miller (2005), Smith e Naylor (2001) e Cavalcanti, Guimarães e Sampaio (2007). Com relação à idade, sua influência ainda é bastante contestada. Alguns autores chegaram a uma correlação negativa de idade e rendimento escolar (BEE; DOLTON, 1985; CLARK; RAMSAY, 1990; GUIMARÃES; SAMPAIO, 2007) e alguns justificam com o argumento de que o estudante que tenha realizado o ensino médio há pouco tempo está em plena atividade intelectual. Porém, outros autores chegaram à relação inversa (SMITH; NAYLOR, 2001; MCINNIS et al., 1995). Estes justificam que estudantes com maior maturidade obtêm melhor desempenho devido a maior clareza quanto à carreira a ser seguida e a necessidade de menor integração na universidade. Uma corrente de pensamento argumenta que a capacidade cognitiva decresce com a idade e, em consequência, o aprendizado é mais fácil em idades mais tenras. Outra argumenta em favor da maturidade, a qual facilita uma compreensão mais ampla e correlaciona-se com a responsabilidade, tornando os alunos mais velhos mais responsáveis e mais dedicados. Outro fator bastante citado na literatura diz respeito ao estado civil do estudante. Smith e Naylor (2001), analisando dados para estudantes universitários no Reino Unido, chegaram à conclusão que estudantes casados têm desempenho superior a estudantes solteiros. Johnes (2006) e Guimarães e Sampaio (2007) obtiveram resultados semelhantes.

A carga de trabalho dos estudantes também tem influência em seu desempenho. Espera-se que estudantes que trabalham apresentem desempenho inferior aos estudantes que não trabalham e, por essa razão, dispõem de mais tempo para se dedicar aos estudos. Porém, segundo Ruhm (1997), que fez longa revisão sobre a influência dessa variável, não há consenso em relação a sua influência real. De um lado, estudantes que pertencem a famílias com maior condição financeira, em geral, devem ter maior desempenho, pois não necessariamente precisam trabalhar. Nesse caso, a importância do apoio financeiro ao estudante é bastante relevante para 
seu desempenho, como indicado na literatura. Por outro lado, uma carga moderada de trabalho, que propicie ao estudante maior conhecimento e aprendizado prático de sua profissão e campo de trabalho, pode influenciar positivamente sua motivação, satisfação e responsabilidade e, em consequência, seu desempenho. Nessa linha, Turner (1994) conclui que, para estudante do ensino médio americano, ter uma carga de trabalho moderada aumenta seu desempenho acadêmico. Stinebrickner e Stinebrickner (2003), no entanto, encontram, após descontar para efeitos como motivação, que o efeito negativo da carga de trabalho sobre o desempenho escolar é ainda maior. Ruhm (1997), analisando a influência do trabalho sobre a renda futura, conclui que o efeito é positivo. Guimarães e Sampaio (2007) encontram que, quanto maior a carga de trabalho dos estudantes, maior é o efeito negativo sobre seu desempenho.

Com relação à influência da família no desempenho dos estudantes, alguns aspectos devem ser analisados. $\mathrm{O}$ ambiente familiar, a educação dos pais, a motivação, o acesso à informação e a renda são fatores considerados de importância significante. Um ambiente familiar estável deve proporcionar maior segurança ao estudante, não gerando impactos negativos em sua personalidade. Este aspecto é bastante contestado quanto a sua significância. A educação dos pais influencia de várias formas: tanto serve como exemplo como pode reforçar a motivação para o estudo, ampliar o acesso à informação e fornecer uma referência quanto às consequências de obter um maior nível educacional. Diversos trabalhos analisam a influência do background familiar no desempenho escolar (SMITH; NAYLOR, 2001; BASSETT et al., 2002; GUIMARÃES; SAMPAIO, 2007). O acesso à informação é um dos aspectos mais importantes, pois amplia a formação e o conhecimento geral e propicia condições para potencializar o estudo. A esse respeito incluem-se tanto acesso a livros, enciclopédias, canais educativos, em televisão fechada, como disponibilidade de informática e Internet. Guimarães e Sampaio (2007) observam que estudantes que acessam a Internet têm melhor desempenho escolar. A renda, por fim, permite a melhoria do ambiente e propicia condições para um melhor acesso à informação e para o atendimento a escolas de melhor nível (ensino privado, no Brasil).

Estudos mostram que o estabelecimento de ensino, a qualidade dos professores, a disponibilidade de laboratórios de qualidade, a organização e o nível dos demais alunos têm influência no desempenho dos estudantes. A qualidade do professor é função do seu conhecimento, que é fruto de sua formação acadêmica, da sua motivação e da sua assiduidade. Todos estes aspectos vão ser de fundamental importância no desempenho do estudante. Bassett et al. (2002), analisando a influência da escolaridade dos professores sobre desempenho no exame de entrada para universidades, chegou à conclusão que o efeito é positivo e maior para os quantis inferiores da distribuição. Para as escolas brasileiras, observa-se uma grande variação nesses indicadores quando se compara o ensino público e privado. Cavalcanti, Guimarães e Sampaio (2007), que analisaram desempenho de estudantes brasileiros no vestibular, chegaram à conclusão que os estudantes de escolas públicas têm desempenho, em média, entre 17-7\% menor que os estudantes de escolas privadas. 


\section{ANÁlise ENVOltória de DAdos (DEA) E A DECOMPOSIÇÃo DA EFICIÊNCIA}

\subsection{A abordagem DEA}

O método da Análise Envoltória de Dados (DEA) possibilita a obtenção de um grau de eficiência para cada unidade tomadora de decisão (Decision Making Unit - DMU). Essas DMUs são avaliadas por suas eficiências relativas às unidades identificadas como eficientes e que compõem a fronteira tecnológica. De acordo com a forma da fronteira, têm-se duas abordagens distintas - a paramétrica e a não-paramétrica. O DEA está inserido na abordagem nãoparamétrica e emprega programação matemática para obter a fronteira de produção. A forma da fronteira do conjunto produtivo é determinada levando em conta que o conjunto de produção deve satisfazer determinadas propriedades. Este método é baseado no trabalho de Farrell (1957), posteriormente estendido por Charnes et al. (1978). No DEA, as DMUs realizam tarefas similares e se diferenciam pelas quantidades dos insumos que consomem e dos produtos que resultam. O conjunto de produção é limitado pela fronteira de produção composta por aquelas DMUs que são eficientes. A determinação das DMUs eficientes é feita por meio da resolução, para cada uma delas, de um sistema de equações lineares definido para mensurar o nível de eficiência de cada DMU. Na análise de ensino, cada aluno representa uma DMU distinta e a eficiência refere-se ao desempenho obtido como função de características pessoais e da instituição.

O modelo proposto por Charnes et al. (1978), com retornos constantes à escala, pode ser resumido supondo-se $\mathrm{N}$ firmas, ou DMUs, utilizando I insumos para produzir $\mathrm{P}$ produtos. $\mathrm{O}$ índice i indica a i-ésima DMU, para a qual os vetores $x_{i}$ e $y_{i}$ representam a quantidade de insumos e produtos. O objetivo é construir uma fronteira não-paramétrica que envolva os dados, de forma que todas as unidades se encontrem sobre ou abaixo desta fronteira. Para cada DMU, maximiza-se a razão entre a soma ponderada dos produtos e dos insumos, onde $u$ é um vetor Pxl dos pesos associados ao produto e $v$ um vetor Ixl dos pesos associados aos insumos. Os valores de $u$ e $v$ são tratados como incógnitas e calculados de forma a maximizar a eficiência de cada DMU. Para cada DMU, é desenvolvido o seguinte problema:

$$
\begin{aligned}
& \operatorname{Max}_{u, v} \quad\left(u^{t} y_{i} / v^{t} x_{i}\right), \\
& \text { sujeito a } \quad\left(u^{t} y_{j} / v^{t} x_{j}\right) \leq 1, \quad j=1, \ldots, N, \\
& u \geq 0 \quad \text { e } \quad v \geq 0
\end{aligned}
$$

O modelo descrito acima apresenta um número infinito de soluções. Pois, se $\left(u^{*}, v^{*}\right)$ é uma solução do problema, então $\left(\alpha u^{*}, \alpha v^{*}\right)$ também é uma solução possível. Esse problema foi resolvido por Charnes et al. (1978), impondo a condição $v^{t} x_{i}=1$. Dessa forma, o novo problema de programação linear é:

$$
\begin{array}{ll}
\operatorname{Max}_{u, v} & u^{t} y_{i}, \\
\text { sujeito a } & v^{t} x_{i}=1,
\end{array}
$$




$$
\begin{array}{r}
u^{t} y_{j}-v^{t} x_{j} \leq 0, \quad j=1, \ldots, N \\
u \geq 0 \quad \text { e } \quad v \geq 0
\end{array}
$$

Essa nova forma é conhecida como forma multiplicativa e apresenta um grande número de restrições, não sendo adequada para efeitos computacionais. Utilizando a propriedade da dualidade da programação linear, o problema pode ser formulado de uma forma equivalente, porém com menos restrições $(\mathrm{I}+\mathrm{P}<\mathrm{N}+1)$, onde $\theta$ é a medida de eficiência, $\lambda$ é um vetor $\mathrm{Nx} 1$ de constantes, $X$ é a matriz de insumos $(\mathrm{IxN})$ e $Y$ é a matriz de produtos $(\mathrm{PxN})$ :

$\operatorname{Min}_{\theta, \lambda} \theta$,

sujeito a $\mathrm{Y} \lambda-\mathrm{y}_{\mathrm{i}} \geq 0$,

$$
\theta \mathrm{x}_{\mathrm{i}}-\mathrm{X} \lambda \geq 0, \lambda \geq 0 \text {. }
$$

O problema de programação linear é resolvido $N$ vezes, uma para cada DMU. O valor de $\theta$ é a medida de eficiência e deve satisfazer a condição $\theta \leq 1$. O uso de retornos constantes de escala, quando nem todas as DMUs estão operando na escala ótima, resulta em medidas de eficiência técnica influenciadas pelas medidas de eficiência de escala. Nestes casos, a abordagem por retornos variáveis de escala permite a medição da eficiência técnica sem a interferência da eficiência de escala. A extensão desse modelo, passando a considerar rendimentos variáveis de escala (VRS), foi feita por Banker et al. (1984), adicionando a restrição de convexidade $\left(z^{t} \lambda=\right.$ 1), obtendo o seguinte problema, onde z é o vetor unitário Nxl:

$$
\begin{aligned}
& \operatorname{Min}_{\theta, \lambda} \theta \\
& \text { sujeito a } \mathrm{Y} \lambda-\mathrm{y}_{\mathrm{i}} \geq 0, \\
& \qquad \\
& \qquad \mathrm{x}_{\mathrm{i}}-\mathrm{X} \lambda \geq 0, \mathrm{z}^{\mathrm{t}} \lambda=1, \mathrm{e} \lambda \geq 0
\end{aligned}
$$

Neste trabalho, é adotado o modelo com orientação para produto com retornos variáveis de escala. A seguir, trataremos em detalhe a decomposição da medida de eficiência, a qual será utilizada nas nossas estimações.

\subsection{Decompondo a eficiência}

Para se calcular a eficiência do estabelecimento de ensino foi utilizada a metodologia primeiramente proposta por Thanassoulis (1999) e depois estendia por Portela e Thanassoulis (2001). Esta metodologia utiliza o método da Análise Envoltória de Dados - DEA - para calcular um coeficiente de eficiência para cada estudante e, em seguida, o separa em dois componentes: (a) um componente correspondente à eficiência do estabelecimento de ensino que o aluno estudou, excluindo características do estudante como, por exemplo, seu esforço e motivação, e (b) outro componente correspondente à eficiência somente do estudante.

A Figura 1 apresenta uma ilustração da decomposição em que cada DMU representa estudantes distintos de diferentes escolas. Supondo a existência de três escolas A, B e C, e sendo a escola A do tipo 2 (T2, por exemplo, pública), e as escolas B e C do tipo 1 (T1, por exemplo, 
privadas). Assumindo que o insumo seja o nível de conhecimento de entrada de cada estudante na escola e o produto seja o nível de conhecimento de saída de cada estudante, pode-se obter a fronteira de produção para cada escola. Essas fronteiras são representadas pelas linhas contínuas e denominadas Fronteiras de Eficiência Local $\left(\mathrm{EF}^{\mathrm{L}}\right)$.

Figura 1 - Decomposição da eficiência utilizando a abordagem DEA

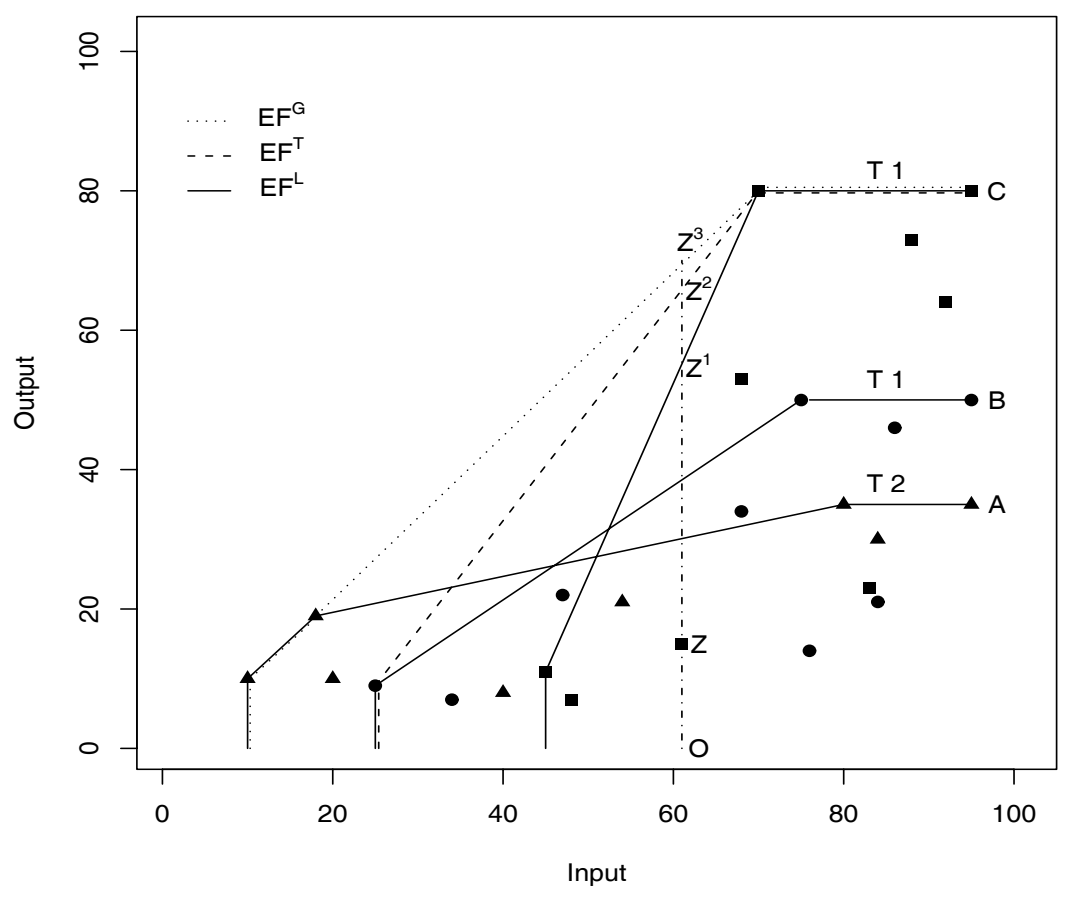

A eficiência dos estudantes em relação a sua escola $\left(\mathrm{EF}_{1}\right)$ pode ser facilmente calculada, dada sua fronteira de eficiência local. Essa eficiência representa somente o efeito do estudante, ou seja, estar compondo a fronteira de sua escola depende exclusivamente do seu nível de esforço e motivação. Para o estudante $Z$, por exemplo, que estudou na escola $C$, sua eficiência é dada pela razão:

$$
\mathrm{EF}_{1}=\frac{O Z}{O Z^{1}}
$$

que tem valor igual a 1, quando o estudante situa-se na fronteira de sua escola, e valor menor que 1 , quando situa-se abaixo da fronteira.

Em relação ao tipo escola, a fronteira ilustrada pela linha tracejada $\left(\mathrm{EF}^{\mathrm{T}}-\right.$ Fronteiras de Eficiência por Tipo) representa a fronteira de produção somente das escolas do mesmo tipo, que, neste caso, foi traçada para as escolas privadas (T1). Essa é a fronteira máxima para todos os estudantes das escolas privadas. Estar sobre essa fronteira depende de dois fatores: primeiro do nível de esforço e motivação do estudante e segundo da qualidade de ensino da escola. Se o 
nível de esforço e motivação do estudante forem maximizados, ainda assim o estudante poderá não alcançar a fronteira de eficiência por tipo para as escolas privadas. Porém, ele não alcançar a eficiência máxima se deve exclusivamente à distância da fronteira do seu estabelecimento de ensino à fronteira de todos os estabelecimentos de ensino privado. ${ }^{3}$ Para o aluno Z, seu coeficiente de eficiência em relação a todos os colégios privados $\left(\mathrm{EF}_{2}\right)$ é dado pela razão:

$$
\mathrm{EF}_{2}=\frac{O Z}{O Z^{2}}
$$

$\mathrm{O}$ segmento $\mathrm{Z}^{1} \mathrm{Z}^{2}$ representa a distância da fronteira do colégio $\mathrm{C}$ em relação à fronteira de todos os colégios privados para o estudante $\mathrm{Z}$. Para se obter a eficiência do colégio $\mathrm{C}$ em relação a todos os colégios privados $\left(\mathrm{EF}_{4}\right)$, procede-se da seguinte maneira:

$\mathrm{EF} 2=\frac{O Z}{O Z^{2}}=\underbrace{\left(\frac{O Z}{O Z^{1}}\right)}_{E F_{1}} \cdot \underbrace{\left(\frac{O Z^{1}}{O Z^{2}}\right)}_{E F_{4}}$

$\mathrm{EF}_{4}=\frac{O Z^{1}}{O Z^{2}}=\frac{E F_{2}}{E F_{1}}$

O mesmo pode ser feito para calcular a eficiência de cada colégio em relação a todos os colégios. Para isso, deve-se calcular a eficiência de cada estudante em relação à fronteira delimitada por todos os colégios $\left(\mathrm{EF}^{\mathrm{G}}\right.$ - Fronteiras de Eficiência Global), sejam privados ou públicos. A eficiência global de cada estudante $\left(\mathrm{EF}_{3}\right)$ pode ser obtida por:

$$
\mathrm{EF}_{3}=\frac{O Z}{O Z^{3}}
$$

Como dito acima, essa eficiência inclui componentes do estudante e do estabelecimento de ensino. Para separar esses componentes e assim obter a eficiência somente do estabelecimento $\left(\mathrm{EF}_{5}\right)$, procede-se da seguinte maneira:

$\mathrm{EF} 3=\frac{O Z}{O Z^{3}}=\underbrace{\left(\frac{O Z}{O Z^{1}}\right)}_{E F_{1}} \cdot \underbrace{\left(\frac{O Z^{1}}{O Z^{3}}\right)}_{E F_{5}}$

$\mathrm{EF}_{5}=\frac{O Z^{1}}{O Z^{3}}=\frac{E F_{3}}{E F_{1}}$

Por fim, para se obter a eficiência dos tipos de colégio em relação a todos os colégios $\left(\mathrm{EF}_{6}\right)$, deve-se calcular o valor de $\frac{O Z^{2}}{O Z^{3}}$ para cada estudante. Este valor pode ser obtido da seguinte
maneira:

3 Seria o caso, por exemplo, se o aluno Z estudasse na escola B. Com motivação e esforços máximos, este alcançaria a eficiência máxima em seu estabelecimento, mas não alcançaria a eficiência máxima em todos os estabelecimentos. 


$$
\mathrm{EF}_{6}=\frac{O Z^{2}}{O Z^{3}}=\left(\frac{O Z^{2}}{O Z}\right) \cdot\left(\frac{O Z}{O Z^{3}}\right)=\frac{E F_{3}}{E F_{2}}
$$

A seguir, descrevemos a base de dados utilizada nas nossas estimações.

\section{BASE DE DADOS E VARIÁVEIS}

\subsection{Base de dados}

A metodologia descrita acima foi aplicada a um conjunto de estabelecimentos de ensino médio localizados na Região Metropolitana do Recife - RMR. A amostra foi retirada da base de dados original que engloba 56.723 alunos que prestaram vestibular para ingressar na Universidade Federal de Pernambuco (UFPE), no ano de 2005. ${ }^{4}$ Foram incluídos na amostra somente estabelecimentos pertencentes à Região Metropolitana do Recife (RMR), pois há alto porcentual de valores não disponíveis ou nulos na variável que identifica o colégio de origem dos estudantes não pertencentes à RMR. Foram incluídos somente alunos que dispunham de todas as variáveis necessárias para a análise. Foram excluídos os estabelecimentos da RMR em que o número total de alunos prestando vestibular foi inferior a 50.

O total de estabelecimentos de ensino da amostra foi de 89, sendo 32 públicos e 57 privados. Do total de estudantes analisados, 17.643 (76,58\%) estudaram em escolas privadas e 5.397 $(23,42 \%)$ estudaram em escolas públicas.

\subsection{Variáveis}

A escolha de insumos e produtos adequados tem sido a busca de diversos autores na utilização da análise envoltória de dados, pois o grande número de variáveis que podem ser utilizadas impossibilita uma comparação mais direta entre as DMUs, não permitindo a generalização dos resultados (BENJAMIN; OBENG, 1990). Para o caso da educação, há diversos fatores que afetam o desempenho dos estudantes, como visto na seção 2, assim como há diversos produtos resultantes da educação. A escola não só tem função de preparar seus alunos para avaliações acadêmicas, mas também para atividades físicas, sociais, de trabalho, etc. Porém, dada a disponibilidade de dados, esta análise concentrou-se apenas no desempenho acadêmico dos alunos.

4 Para selecionar os alunos que pertencem a que rede de ensino (pública/privada), utilizou-se uma variável que identifica o colégio em que o estudante concluiu o ensino médio. Esta variável, porém, não considera diferenças entre estudantes que cursaram apenas parte do ensino médio em uma das redes de ensino. No entanto, o porcentual de alunos que cursaram apenas um ou dois anos do ensino médio na rede pública representa pouco menos de $5 \%$ do total da amostra. Com isso, utilizar o colégio que o estudante concluiu o ensino médio para separar os estudantes entre as redes não gera grandes distorções à análise. 
Nesse sentido, seria razoável escolher insumos e produtos que refletissem o nível de conhecimento dos alunos antes e depois de realizarem seus estudos. Portela e Thanassoulis (2001) utilizaram como insumos e produtos proxies para o nível inicial e final de habilidade do estudante, sendo representadas pela pontuação total e ponderada de exames realizados antes e depois da realização do curso universitário. Johnes (2006) utilizou somente um insumo, representado pelo argumento de classificação de entrada na universidade, e um produto, representado pelo aproveitamento acadêmico do aluno na universidade.

Neste artigo, adotou-se como produto uma proxy para o nível de conhecimento ao fim dos estudos, dado pelo argumento de classificação no vestibular ${ }^{5}$ (NOTAVEST). Este produto reflete influências de características pessoais e sociais, cognitivas e demográficas dos estudantes, da qualidade e da eficiência do estabelecimento de ensino e do ambiente familiar.

Para obter o valor da nota descontada (NOTADESC) pelos fatores citados, foi utilizado o erro $(\hat{\varepsilon})$ da regressão estimada por Guimarães e Sampaio (2007), que, como foi dito, utilizaram a mesma base de dados utilizada nesta análise. ${ }^{6}$ Foi criado um erro modificado $(\overline{\hat{\varepsilon}})$, que é utilizado para obtenção do insumo, a partir da equação $Y-X \hat{\beta}=\overline{\hat{\varepsilon}}$, onde $\mathrm{X}$ é um vetor que representa um subconjunto das variáveis utilizadas na regressão e apresentadas na Tabela 1. Ou seja, o vetor $\mathrm{X}$ comporta variáveis que captem características pessoais e demográficas dos estudantes como, por exemplo, idade, renda, número de filhos, educação dos pais, carga de trabalho, raça, religião, entre outros. Os regressores que pertencem à regressão estimada, porém não pertencem ao vetor $\mathrm{X}$, correspondem a variáveis que dizem respeito à instituição de ensino. Portanto, o erro $\overline{\hat{\varepsilon}}$ representa uma modificação do erro da equação estimada $\hat{\varepsilon}$. Porém, os erros $\overline{\hat{\varepsilon}}$ apresentam valores positivos e negativos, o que seria incompatível com a estimação do modelo DEA, pois não pode haver insumos negativos. Então, somou-se uma constante aos erros modificados e à NOTAVEST para que todos os insumos ficassem não negativos. Esse procedimento de translação dos insumos e produtos, sob retornos variáveis de escala (VRS) e orientação para produto, não afeta a ordem das eficiências obtidas, como constatado por Cooper et al. (2000).

Como dito acima, foi adotado o modelo DEA proposto por Banker et al. (1984) que assume retornos variáveis de escala (VRS). Isso se deve ao fato de que, se a nota no vestibular (NOTAVEST) de um estudante for n vezes maior que a de outro, não há razões para esperar que a nota descontada (NOTADESC) do primeiro estudante seja também n vezes maior que a do segundo (Johnes, 2006). Uma descrição das variáveis socioeconômicas é apresentada na Tabela 1, comparando alunos da rede privada e pública.

5 Neste caso, o argumento de classificação é representado pela nota do aluno na $1^{\mathrm{a}}$ etapa do vestibular, dado que a prova realizada nesta etapa é a mesma para todos os alunos. $\mathrm{Na} 2^{\mathrm{a}}$ etapa, a prova varia em função do curso desejado pelo aluno.

6 Para mais detalhes, ver Guimarães e Sampaio (2007). Ver também Cavalcanti, Guimarães e Sampaio (2007). 


\subsection{Estatísticas descritivas}

Pode-se observar que o desempenho dos alunos da rede pública é inferior ao desempenho dos alunos da rede privada. Isso se deve à soma de diversos fatores. $\mathrm{O}$ fato de o aluno estudar em escola paga já é reflexo de uma melhor condição econômica por parte da família, a qual, possivelmente, está correlacionada com o nível de instrução dos pais. Isso pode ser visto na Tabela 1, em que a renda média dos estudantes das escolas privadas é três vezes maior que a renda média dos estudantes das escolas públicas. Com relação à educação dos pais, observa-se também que a diferença é de quase quatro anos de estudo. Estes dois fatores disponibilizam um ambiente altamente propício para o desenvolvimento intelectual do indivíduo. Uma consequência direta desses dois fatores é o acesso à informação que pode ser observado na diferença do uso da Internet, o qual é três vezes maior para os estudantes de escolas privadas.

Com relação a horas trabalhadas, os estudantes de escolas públicas, provavelmente devido a menor renda, têm uma carga de trabalho 2,5 vezes maior que a dos estudantes da rede privada. Esse fator, como indicado na revisão bibliográfica, pode ter influência negativa ou positiva. Porém, Guimarães e Sampaio (2007) estimaram regressão para a mesma base de dados utilizada neste estudo e obtiveram que a influência das horas de trabalho no desempenho do aluno é negativa e seu efeito aumenta quanto maior for o desempenho do aluno, condicionada a outros fatores sociodemográficos.

A soma de fatores como baixa renda, baixa educação dos pais e maior carga de trabalho, entre outros, faz com que o sistema público apresente alto índice de retenção. A idade média de conclusão do ensino médio dos estudantes da rede pública é de 20,2 anos, enquanto que dos estudantes da rede privada é de 17,1. Isso tem efeito direto na nota do estudante no exame do vestibular, dado que a idade exerce influência negativa sobre o desempenho escolar (GUIMARÃES; SAMPAIO, 2007). A taxa de fecundidade também é distinta. O número de filhos é maior para as alunas de escolas públicas. A proporção de mães em relação ao total de mulheres também é maior, sendo de mais de duas vezes a diferença entre alunas de escolas públicas $(4,45 \%)$ e de escolas privadas $(1,92 \%)$.

Esse conjunto de fatores acaba também por afetar o número de vezes que o estudante realiza o exame vestibular. $\mathrm{O}$ número de vestibulares prestados por estudantes da rede pública é $13,35 \%$ maior que o número de vestibulares prestados por estudantes da rede privada.

A composição racial também varia entre as duas redes de ensino. No ensino privado, as famílias têm maior poder aquisitivo e o porcentual de brancos e negros é de 56,58\% e 5,63\%, respectivamente. Para o ensino público, 13,6\% são negros e $34 \%$ são brancos. Com respeito a pardos, $45 \%$ dos estudantes de escolas públicas declaram-se assim e $32 \%$ dos de escolas privadas também o fazem.

Pode-se observar ainda outras diferenças entre as redes de ensino público e privado. A proporção de estudantes casados é quatro vezes maior no ensino público do que no ensino privado. Note que esta é uma variável que afeta positivamente o desempenho escolar segundo Guimarães e Sampaio (2007). A proporção de alunos que tiveram aulas de laboratório durante 
o ensino fundamental é maior para a rede privada. O mesmo serve para aulas em cursinho privado, que exercem influência positiva no desempenho. A proporção de estudantes prestando vestibular por experiência também é maior no ensino privado. Isso se deve a maior renda dos estudantes, dado o custo para realização do exame, e tem impacto positivo no desempenho futuro, visto que quanto maior o número de vestibulares prestados, melhor é o desempenho dos alunos (GUIMARÃES; SAMPAIO, 2007). A proporção de estudantes que fez supletivo é maior no ensino privado e, como mostra Guimarães e Sampaio (2007), esta variável tem efeito negativo no desempenho. Por fim, a porcentagem de alunos que tem hábito de leitura é maior no ensino público.

\section{Tabela 1 - Estatísticas básicas}

\begin{tabular}{|c|c|c|c|c|}
\hline & \multicolumn{2}{|c|}{ Privado (17.643) } & \multicolumn{2}{|c|}{ Público (5.397) } \\
\hline Variáveis & Média & Desv. Pad. & Média & Desv. Pad \\
\hline Nota & 4,793 & 1,389 & 4,135 & 1,314 \\
\hline Idade & 18,789 & 3,225 & 22,184 & 6,068 \\
\hline Filhos por Aluna & 1,384 & 0,622 & 1,585 & 0,706 \\
\hline Número de Vestibulares & 1,775 & 0,943 & 2,012 & 1,049 \\
\hline Educação do Pai & 13,664 & 3,816 & 10,041 & 3,864 \\
\hline Educação da Mãe & 13,909 & 3,757 & 9,963 & 3,816 \\
\hline Horas de Trabalho & 0,959 & 2,276 & 2,435 & 3,356 \\
\hline Renda Mensal (R\$) & $2.516,237$ & $2.556,961$ & 807,3 & 951,266 \\
\hline Variáveis Binárias & & $\%$ & & $\%$ \\
\hline Casado & 377 & 2,14 & 480 & 8,89 \\
\hline Mora com Pais & 15.368 & 87,11 & 4.350 & 80,60 \\
\hline Fez Supletivo & 175 & 0,99 & 30 & 0,56 \\
\hline Usuário de Internet & 9.696 & 54,96 & 987 & 18,29 \\
\hline Aulas de Laboratório & 8.940 & 50,67 & 1.506 & 27,90 \\
\hline Língua Estrangeira & 1.112 & 6,30 & 103 & 1,91 \\
\hline Cursinho Privado & 9.025 & 51,15 & 1.815 & 33,63 \\
\hline Vestibular por Experiência & 1.308 & 7,41 & 30 & 0,56 \\
\hline Hábito de Leitura & 3.407 & 19,31 & 1.931 & 35,78 \\
\hline \multicolumn{5}{|l|}{ · Religião } \\
\hline Católica & 11.298 & 64,04 & 2.578 & 47,77 \\
\hline Evangélica & 2.591 & 14,69 & 1.622 & 30,05 \\
\hline Afroreligião & 63 & 0,36 & 34 & 0,63 \\
\hline Judeu & 40 & 0,23 & 4 & 0,07 \\
\hline \multicolumn{5}{|l|}{ - Raça } \\
\hline Branca & 9.982 & 56,58 & 1.899 & 35,19 \\
\hline Parda & 5.546 & 31,44 & 2,419 & 44,83 \\
\hline Amarela & 852 & 4,83 & 227 & 4,21 \\
\hline Indígena & 267 & 1,51 & 94 & 1,74 \\
\hline Negra & 993 & 5,63 & 758 & 14,04 \\
\hline
\end{tabular}

A Figura 2 apresenta as distribuições das notas do total de alunos, representado pela linha contínua; dos alunos dos colégios públicos, representado pela linha pontilhada, e dos alunos dos 
colégios privados, representado pela linha tracejada. Observa-se que a distribuição das notas dos estudantes dos colégios públicos localiza-se à esquerda da distribuição das notas dos estudantes dos colégios privados. Isso implica que há uma grande massa de estudantes dos colégios públicos com notas relativamente mais baixas que os estudantes de colégios privados.

Figura 2 - Distribuição das notas para as escolas públicas e privadas

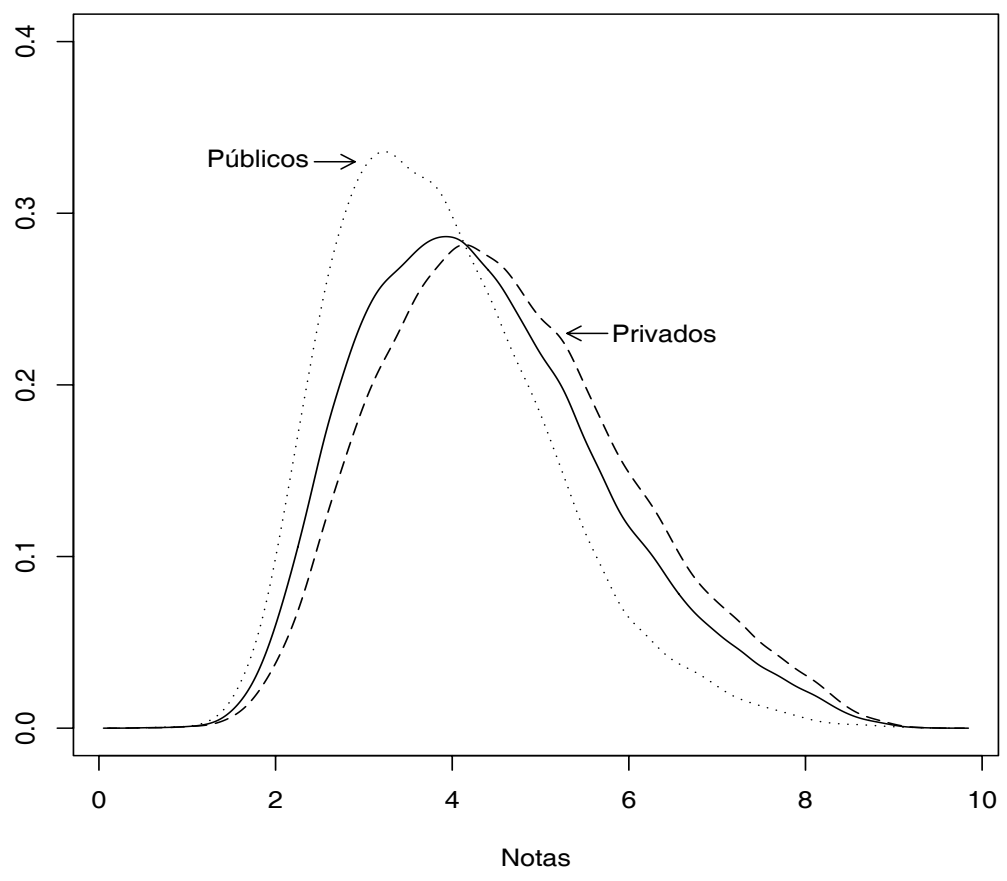

\section{ANÁLISE E RESUltados}

Foram estimados seis tipos de eficiência. Com relação aos estudantes, $\mathrm{EF}_{1}$ corresponde à eficiência do estudante em relação a sua escola, $\mathrm{EF}_{2}$ corresponde à eficiência do estudante $\mathrm{em}$ relação a todas as escolas do mesmo tipo que a sua (Privada, Pública Estadual ou Federal) e $\mathrm{EF}_{3}$ corresponde à eficiência do estudante em relação a todas as escolas. Com relação aos estabelecimentos de ensino, $\mathrm{EF}_{4}$ corresponde à eficiência da escola em relação a todas as escolas do mesmo tipo, $\mathrm{EF}_{5}$ corresponde à eficiência da escola em relação a todas as escolas analisadas e $\mathrm{EF}_{6}$ corresponde à eficiência dos tipos de escolas em relação a todos os tipos, ou seja, a diferença de eficiência dos sistemas de ensino privado, público estadual e público federal. 
Tabela 2 - Eficiências médias por estabelecimento de ensino

\begin{tabular}{|c|c|c|c|c|c|c|c|c|c|c|c|c|c|}
\hline Tipo & $\%$ Apr. & $\mathrm{EF}_{1}$ & $\mathrm{EF}_{2}$ & $\mathrm{EF}_{3}$ & $\mathrm{EF}_{4}$ & $\mathrm{EF}_{5}^{*}$ & Tipo & $\%$ Apr. & $\mathrm{EF}_{1}$ & $\mathrm{EF}_{2}$ & $\mathrm{EF}_{3}$ & $\mathrm{EF}_{4}$ & $\mathrm{EF}_{5}^{*}$ \\
\hline Priv. & 13,28 & 0,725 & 0,709 & 0,709 & 0,98 & 0,98 & Priv. & 8,07 & 0,754 & 0,611 & 0,611 & 0,809 & 0,809 \\
\hline Priv. & 21,26 & 0,792 & 0,766 & 0,766 & 0,967 & 0,967 & Priv. & 12,28 & 0,766 & 0,616 & 0,616 & 0,809 & 0,809 \\
\hline Priv. & 11,58 & 0,722 & 0,697 & 0,697 & 0,965 & 0,965 & Priv. & 4,41 & 0,753 & 0,604 & 0,604 & 0,805 & 0,805 \\
\hline Priv. & 18,14 & 0,747 & 0,719 & 0,719 & 0,964 & 0,964 & Púb. & 14,61 & 0,772 & 0,682 & 0,621 & 0,883 & 0,803 \\
\hline Priv. & 15,09 & 0,768 & 0,74 & 0,74 & 0,963 & 0,963 & Priv. & 7,52 & 0,739 & 0,587 & 0,587 & 0,797 & 0,797 \\
\hline Priv. & 15,34 & 0,773 & 0,742 & 0,742 & 0,962 & 0,962 & Priv. & 8,33 & 0,795 & 0,63 & 0,63 & 0,795 & 0,795 \\
\hline Priv. & 11,63 & 0,733 & 0,701 & 0,701 & 0,959 & 0,959 & Priv. & 9,74 & 0,788 & 0,626 & 0,626 & 0,794 & 0,794 \\
\hline Priv. & 13,90 & 0,752 & 0,713 & 0,713 & 0,948 & 0,948 & Priv. & 12,24 & 0,811 & 0,642 & 0,642 & 0,791 & 0,791 \\
\hline Priv. & 15,17 & 0,729 & 0,691 & 0,691 & 0,947 & 0,947 & Púb. & 7,71 & 0,722 & 0,639 & 0,571 & 0,884 & 0,79 \\
\hline Priv. & 12,84 & 0,714 & 0,675 & 0,675 & 0,945 & 0,945 & Púb. & 11,92 & 0,755 & 0,652 & 0,59 & 0,866 & 0,782 \\
\hline Priv. & 15,49 & 0,762 & 0,72 & 0,72 & 0,945 & 0,945 & Priv. & 4,48 & 0,773 & 0,6 & 0,6 & 0,779 & 0,779 \\
\hline Priv. & 11,67 & 0,721 & 0,673 & 0,673 & 0,936 & 0,936 & Púb. & 10,79 & 0,726 & 0,629 & 0,565 & 0,866 & 0,778 \\
\hline Priv. & 15,12 & 0,788 & 0,728 & 0,728 & 0,923 & 0,923 & Púb. & 9,56 & 0,73 & 0,632 & 0,568 & 0,866 & 0,777 \\
\hline Priv. & 16,80 & 0,763 & 0,703 & 0,703 & 0,921 & 0,921 & Priv. & 3,85 & 0,702 & 0,544 & 0,544 & 0,777 & 0,777 \\
\hline Priv. & 13,08 & 0,746 & 0,686 & 0,686 & 0,92 & 0,92 & Priv. & 21,82 & 0,846 & 0,657 & 0,657 & 0,777 & 0,777 \\
\hline Priv. & 10,30 & 0,687 & 0,629 & 0,629 & 0,917 & 0,917 & Priv. & 16,33 & 0,833 & 0,646 & 0,646 & 0,776 & 0,776 \\
\hline Priv. & 16,28 & 0,844 & 0,763 & 0,763 & 0,904 & 0,904 & Priv. & 6 & 0,801 & 0,614 & 0,614 & 0,771 & 0,771 \\
\hline Priv. & 14,96 & 0,747 & 0,674 & 0,674 & 0,904 & 0,904 & Púb. & 9,09 & 0,71 & 0,606 & 0,546 & 0,855 & 0,769 \\
\hline Priv. & 14,93 & 0,784 & 0,703 & 0,703 & 0,898 & 0,898 & Púb. & 7,53 & 0,711 & 0,611 & 0,546 & 0,86 & 0,767 \\
\hline Púb. & 25,63 & 0,799 & 0,77 & 0,715 & 0,965 & 0,895 & Púb. & 5,23 & 0,705 & 0,596 & 0,53 & 0,847 & 0,752 \\
\hline Priv. & 16,31 & 0,745 & 0,665 & 0,665 & 0,892 & 0,892 & Priv. & 3,23 & 0,768 & 0,576 & 0,576 & 0,749 & 0,749 \\
\hline Púb. & 24,87 & 0,765 & 0,738 & 0,679 & 0,965 & 0,887 & Priv. & 8,54 & 0,77 & 0,576 & 0,576 & 0,749 & 0,749 \\
\hline Priv. & 12,62 & 0,801 & 0,708 & 0,708 & 0,885 & 0,885 & Púb. & 6,02 & 0,729 & 0,61 & 0,545 & 0,838 & 0,748 \\
\hline Priv. & 13,53 & 0,736 & 0,649 & 0,649 & 0,883 & 0,883 & Púb. & 5,25 & 0,725 & 0,604 & 0,542 & 0,836 & 0,748 \\
\hline Priv. & 5,75 & 0,699 & 0,614 & 0,614 & 0,882 & 0,882 & Púb. & 3,86 & 0,701 & 0,58 & 0,517 & 0,828 & 0,739 \\
\hline Priv. & 7,77 & 0,768 & 0,674 & 0,674 & 0,878 & 0,878 & Púb. & 4,26 & 0,735 & 0,603 & 0,538 & 0,821 & 0,732 \\
\hline Priv. & 22,86 & 0,858 & 0,743 & 0,743 & 0,868 & 0,868 & Púb. & 2,99 & 0,744 & 0,601 & 0,54 & 0,811 & 0,728 \\
\hline Priv. & 11,50 & 0,724 & 0,622 & 0,622 & 0,861 & 0,861 & Púb. & 3,08 & 0,707 & 0,575 & 0,514 & 0,815 & 0,727 \\
\hline Priv. & 10,00 & 0,765 & 0,656 & 0,656 & 0,859 & 0,859 & Priv. & 1,67 & 0,777 & 0,561 & 0,561 & 0,724 & 0,724 \\
\hline Priv. & 10,32 & 0,708 & 0,596 & 0,596 & 0,849 & 0,849 & Púb. & 3,8 & 0,761 & 0,612 & 0,548 & 0,807 & 0,723 \\
\hline Púb. & 39,86 & 0,863 & 0,785 & 0,732 & 0,91 & 0,847 & Púb. & 10,71 & 0,756 & 0,611 & 0,542 & 0,81 & 0,718 \\
\hline Priv. & 10,00 & 0,79 & 0,663 & 0,663 & 0,84 & 0,84 & Priv. & 2 & 0,814 & 0,584 & 0,584 & 0,718 & 0,718 \\
\hline Priv. & 13,22 & 0,794 & 0,666 & 0,666 & 0,839 & 0,839 & Púb. & 3,23 & 0,724 & 0,575 & 0,517 & 0,798 & 0,717 \\
\hline Priv. & 10,42 & 0,785 & 0,653 & 0,653 & 0,833 & 0,833 & Púb. & 2,5 & 0,738 & 0,576 & 0,52 & 0,783 & 0,704 \\
\hline Priv. & 8,34 & 0,727 & 0,606 & 0,606 & 0,833 & 0,833 & Púb. & 8,4 & 0,775 & 0,599 & 0,542 & 0,773 & 0,7 \\
\hline Priv. & 8,38 & 0,756 & 0,628 & 0,628 & 0,831 & 0,831 & Púb. & 5,46 & 0,731 & 0,563 & 0,506 & 0,773 & 0,694 \\
\hline Priv. & 13,19 & 0,773 & 0,642 & 0,642 & 0,831 & 0,831 & Púb. & 7,62 & 0,74 & 0,569 & 0,511 & 0,769 & 0,69 \\
\hline Priv. & 7,35 & 0,804 & 0,666 & 0,666 & 0,83 & 0,83 & Púb. & 8,2 & 0,794 & 0,609 & 0,547 & 0,766 & 0,687 \\
\hline Priv. & 8,64 & 0,737 & 0,612 & 0,612 & 0,83 & 0,83 & Púb. & 7,41 & 0,795 & 0,606 & 0,543 & 0,766 & 0,686 \\
\hline Priv. & 6,23 & 0,721 & 0,593 & 0,593 & 0,823 & 0,823 & Púb. & 7,23 & 0,796 & 0,603 & 0,543 & 0,762 & 0,685 \\
\hline Priv. & 7,81 & 0,738 & 0,604 & 0,604 & 0,82 & 0,82 & Púb. & 4,29 & 0,759 & 0,578 & 0,518 & 0,766 & 0,684 \\
\hline Priv. & 4,86 & 0,774 & 0,635 & 0,635 & 0,819 & 0,819 & Púb. & 4,11 & 0,815 & 0,586 & 0,523 & 0,72 & 0,643 \\
\hline Púb. & 13,16 & 0,722 & 0,647 & 0,583 & 0,903 & 0,814 & Púb. & 3,33 & 0,795 & 0,565 & 0,507 & 0,715 & 0,642 \\
\hline Priv. & 10,29 & 0,754 & 0,613 & 0,613 & 0,812 & 0,812 & Púb. & 1,45 & 0,772 & 0,551 & 0,489 & 0,713 & 0,633 \\
\hline Priv. & 11,39 & 0,811 & 0,656 & 0,656 & 0,809 & 0,809 & & & & & & & \\
\hline
\end{tabular}

Notas: Os estabelecimentos de ensino estão classificados em ordem decrescente de $\mathrm{EF}_{5}$. 
Os resultados de eficiência em relação aos estudantes proporcionam ao estabelecimento de ensino boa fonte de informação para formulação de políticas, buscando melhorar a eficiência e a qualidade do ensino. Através da eficiência do estudante em relação ao seu estabelecimento, pode-se ter uma medida de esforço e motivação e, assim, buscar entender quais as possíveis causas de eventual desmotivação e o que pode ser feito para que isto se reverta, elevando seu nível de aprendizado e aproximando-os da fronteira local. A eficiência da escola para cada estudante também pode ajudar a identificar para quais estudantes a escola não está sendo eficiente e que atitudes tomar para que o ensino ganhe eficiência e eficácia.

Os resultados médios das eficiências para cada estabelecimento de ensino analisado são apresentados na Tabela 2. Para as eficiências médias dos estudantes em relação à sua escola $\left(\mathrm{EF}_{1}\right)$, o colégio que obteve maior coeficiente é público federal (terceiro colocado entre os públicos federais na ordem indicada na Tabela 2), com 0,863. O segundo, terceiro e quarto lugares foram ocupados por escolas privadas. Essa eficiência representa a distância média dos estudantes em relação a sua fronteira local e é uma medida de motivação dos alunos. Tanto essa medida de eficiência quanto a eficiência média dos estudantes em relação a todas as escolas do mesmo tipo $\left(\mathrm{EF}_{2}\right)$ subestimam a eficiência real dos estudantes, pois não levam em conta a eficiência do estabelecimento de ensino, que afeta diretamente o desempenho do estudante (output).

Nesse sentido, por meio da metodologia detalhada acima, pôde-se isolar o efeito apenas do estabelecimento de ensino $\left(\mathrm{EF}_{5}\right)$. Estes estão ordenados na Tabela $2 \mathrm{em}$ ordem decrescente. Pode-se observar que os colégios privados concentram-se, de modo geral, acima dos colégios públicos. Dos cinquenta primeiros colégios, há somente cinco públicos, dos quais, os três melhores colocados são federais. Do mesmo modo, dos últimos 20 colocados, há somente dois privados. Nesta tabela, também se apresenta o porcentual de alunos aprovados no vestibular para ilustrar que o estabelecimento de ensino mais eficiente não necessariamente é o estabelecimento que aprova um maior número de alunos. Pode-se ter um estabelecimento que tenha eficiência máxima, porém o nível de entrada dos alunos é tão baixo que o nível final de conhecimento desses alunos não permite que eles sejam aprovados no vestibular. O mesmo serve para um estabelecimento que não tenha eficiência tão elevada, porém o nível de entrada dos alunos é tão alto, que o nível de conhecimento final dos alunos permite que eles sejam aprovados. Por exemplo, o terceiro colocado entre os colégios públicos federais e trigésimo primeiro entre todos os colégios analisados apresentou um índice de aprovação de quase 40\%. Da mesma forma, para os colégios públicos federais em geral, que não estão entre os mais eficientes, o índice de aprovação é, em média, quase três vezes maior que o índice de aprovação dos colégios privados (ver Tabela 3). É reconhecido que o índice de aprovação esconde o fato de que determinados colégios podem estar aprovando mais alunos em curso de baixa concorrência, ou seja, colégios com mesmo índice de aprovação podem apresentar perfis completamente distintos quanto aos cursos de entrada de seus alunos.

As estimações quanto aos diferentes tipos de estabelecimentos de ensino (Privado, Público Estadual ou Federal) são apresentadas na Tabela 3. A eficiência com relação ao tipo de estabelecimento $\left(\mathrm{EF}_{6}\right)$ mostra que a fronteira global é determinada somente por estudantes da rede privada, dado que o coeficiente médio para os estabelecimentos privados foi de 1,00, ou seja, nenhuma fronteira local dos colégio públicos tangenciou a fronteira de eficiência global. 
A distância média da fronteira de eficiência por tipo, para a fronteira global dos estabelecimentos públicos, foi de 0,901. Para saber a distância média da fronteira por tipo à global, para os estabelecimentos públicos federais e estaduais, foram estimadas mais duas fronteiras, sendo as eficiências médias calculadas de 0,910 e 0,879 , respectivamente.

A eficiência média dos estabelecimentos privados, públicos e públicos federais e estaduais também é apresentada $\left(\mathrm{EF}_{5}\right)$. Observa-se que a eficiência média dos estabelecimentos privados é de 0,904, dos públicos, 0,772, sendo a dos públicos federais de 0,883 e dos estaduais de 0,749. Isso mostra que o ensino público federal obtém níveis de eficiência muito próximos dos níveis de eficiência do ensino privado e muito mais elevados que o sistema de ensino público estadual.

Por meio dos coeficientes de eficiência dos colégios $\left(\mathrm{EF}_{5}\right)$, estimados para cada estudante, pode-se obter o desvio padrão dessa eficiência para analisar quais colégios apresentam ensino mais uniforme, ou seja, que colégios têm sua fronteira de eficiência variando de forma mais próxima da variação da fronteira de eficiência global, caracterizando-o como um colégio que atenda a todos os estudantes de forma única e que seja, portanto, igualmente eficiente para todos os alunos. A Tabela 4 apresenta a eficiência e o desvio padrão para os três colégios mais eficientes de cada tipo. Dentre os três melhores colégios de cada categoria para os diferentes níveis de entrada dos alunos, os colégios com menores dispersões e que, portanto, têm ensino mais uniforme, foram os colégios privados, com destaque para o colégio 3; dos colégios públicos federais, o colégio com eficiência mais uniforme foi o 2; dos colégios públicos estaduais, destaca-se o colégio 2, porém ainda com maior dispersão que os colégios privados. A Tabela 4 apresenta também o desvio padrão de cada sistema de ensino considerada a amostra total. Observa-se que o sistema de ensino público federal é o que apresenta menor dispersão, seguido do sistema privado e do sistema público estadual.

Tabela 3 - Eficiências médias por tipo de estabelecimento de ensino

\begin{tabular}{lrcccccl}
\hline Tipo & $\% \mathrm{Apr}$. & $\mathrm{EF}_{1}$ & $\mathrm{EF}_{2}$ & $\mathrm{EF}_{3}$ & $\mathrm{EF}_{4}$ & $\mathrm{EF}_{5}$ & $\mathrm{EF}_{6}$ \\
\hline Privado & 11,20 & 0,743 & 0,671 & 0,671 & 0,904 & 0,904 & 1 \\
Público & 8,85 & 0,744 & 0,637 & 0,575 & 0,856 & 0,772 & 0,901 \\
Federal & 30,12 & 0,784 & 0,75 & 0,693 & 0,958 & 0,883 & 0,91 \\
- Estadual & 6,65 & 0,736 & 0,614 & 0,551 & 0,836 & 0,749 & 0,879 \\
\hline
\end{tabular}

Notas: Para se obter as diferenças de eficiência entre o sistema federal e estadual, foi estimada nova Fronteira de Eficiência por Tipo $\left(\mathrm{EF}^{\mathrm{T}}\right)$, separando os colégios federais e estaduais.

Tabela 4 - Eficiências dos três colégios mais eficientes de cada tipo

\begin{tabular}{ccccccccc}
\hline Privados & \multicolumn{2}{c}{$\mathrm{EF}_{5}$} & Púb. Federais & \multicolumn{2}{c}{$\mathrm{EF}_{5}$} & Púb. Estaduais & \multicolumn{2}{c}{$\mathrm{EF}_{5}$} \\
\hline 4222 & 0,980 & $(0,030)$ & 1002 & 0,895 & $(0,077)$ & 2002 & 0,814 & $(0,094)$ \\
4065 & 0,967 & $(0,018)$ & 1003 & 0,887 & $(0,024)$ & 4103 & 0,803 & $(0,045)$ \\
4025 & 0,965 & $(0,015)$ & 1001 & 0,847 & $(0,070)$ & 2027 & 0,790 & $(0,036)$ \\
\hline Priv. & 0,904 & $(0,069)$ & Pub. Fed. & 0,883 & $(0,048)$ & Pub. Est. & 0,749 & $(0,058)$ \\
\hline
\end{tabular}

Notas: Desvio padrão é apresentado entre parênteses. 
Dado que os colégios atendem, em termos de eficiência, de forma distinta os diferentes tipos de alunos, seria bastante útil analisar para que nível de aluno o colégio pode exercer maior impacto no desempenho, isto é, como é o comportamento da fronteira de eficiência em função da nota descontada de cada aluno. A Figura 3 representa esse comportamento para os três colégios mais eficientes de cada tipo. A primeira linha da figura representa os colégios privados e a segunda e terceira linhas representam os colégios públicos federais e estaduais, respectivamente. As linhas tracejadas representam a eficiência média.

Para os colégios privados, observa-se que o colégio 1 apresenta crescimento de eficiência para níveis de aluno, variando até 5, quando atinge eficiência máxima, porém, para alunos com nível de entrada superior a 5, o desempenho do colégio começa a decrescer e, a partir de 6, apresenta-se menor que a média, chegando a atingir quase 0.91 de eficiência para alunos com níveis de entrada próximo de 8 . O colégio privado 2 apresenta valores crescentes de eficiência para crescentes níveis de entrada dos alunos, ou seja, desempenho abaixo da média para os piores alunos e desempenho perto de 1 para alunos com alto nível de entrada. Já o colégio privado 3 apresenta crescimento de eficiência até próximo do nível de entrada 3, quando está acima da média. A partir do nível 3, sofre inversão, tendo desempenho inferior à média para alunos com nível de entrada 5, quando inverte novamente, crescendo até atingir eficiência máxima no nível 7. A partir desse valor, inicia uma queda de eficiência.

Os colégios públicos federais apresentam, de maneira geral, fronteira de eficiência crescente, ou seja, quanto maior o nível de entrada do aluno maior será a influência do colégio em sua nota de saída. Para os colégios públicos estaduais, destaca-se o colégio mais eficiente, que apresenta queda bastante significativa a partir da nota de entrada 5, mostrando que o colégio não é eficiente para alunos com melhores níveis de entrada.

Esta análise mostra que, apesar de os estabelecimentos de ensino serem eficientes na média, esta eficiência pode variar bastante dependendo dos níveis de entrada dos alunos. Por exemplo, o colégio privado mais eficiente apresenta eficiência bastante reduzida para os alunos com melhor nível de entrada, sendo comparada à eficiência dos melhores alunos que entram no colégio público federal 2, como mostra a Figura 3.

7 São apresentadas figuras apenas para os três colégios mais eficientes de cada tipo, mas os autores dispõem das mesmas para todos os colégios. Vale salientar que as conclusões referem-se apenas aos colégios cujas figuras são apresentadas, não se tirando inferências para o total da amostra. 
Figura 3 - Eficiência dos colégios para diferentes níveis de entrada dos alunos

Priv. 1

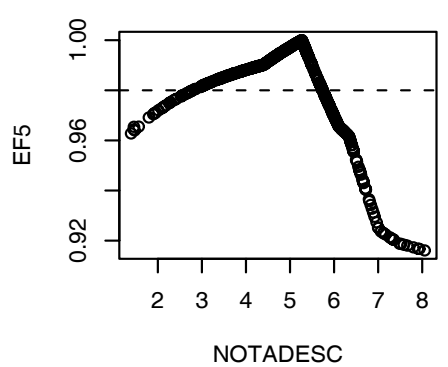

Pub. Fed. 1

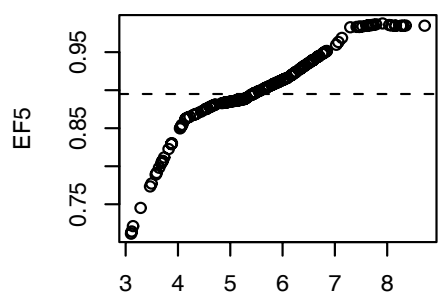

NOTADESC

Pub. Est. 1

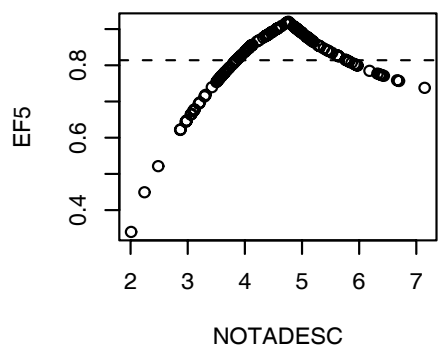

Priv. 2

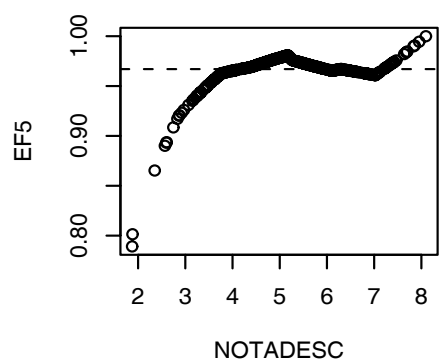

Pub. Fed. 2

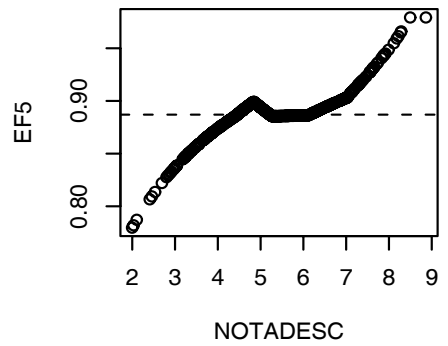

Pub. Est. 2

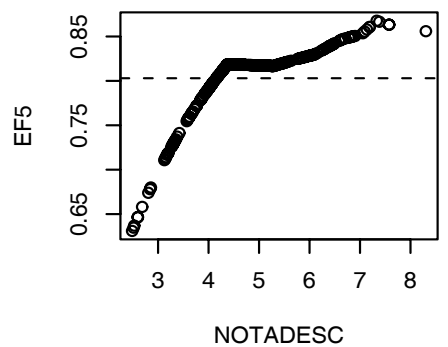

Priv. 3

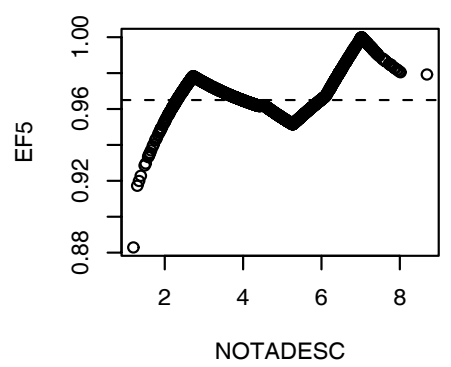

Pub. Fed. 3

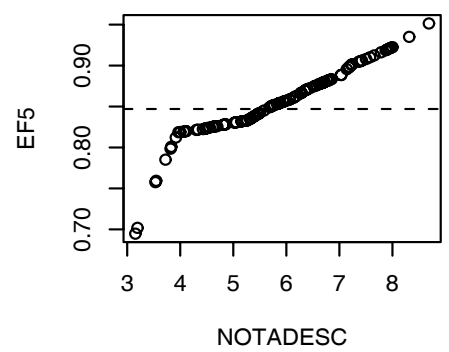

Pub. Est. 3

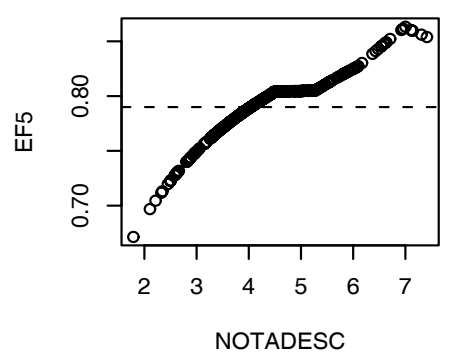

Notas: Os colégios 4025, 4065 e 4222 representam os colégios privados com maiores eficiências. Os colégios 1002 , 1001 e 1003 representam os colégios públicos federais com maiores eficiências. Os colégios 2002, 2093 e 4103 representam os colégios públicos estaduais com maiores eficiências.

A Figura 4 apresenta o comportamento das fronteiras de eficiência por tipo para os colégios públicos federais e estaduais. Observa-se que, para os alunos com nível de entrada inferior a 5, ambos os sistemas de ensino apresentam eficiências bastante semelhantes. Porém, para alunos com nível de entrada superior a 5, os colégios do sistema federal apresentam-se com eficiências muito superiores aos colégios do sistema estadual, chegando quase a 100\% de eficiência para os alunos com alto nível de entrada. 
Figura 4 - Eficiência dos colégios públicos para diferentes níveis de entrada dos alunos

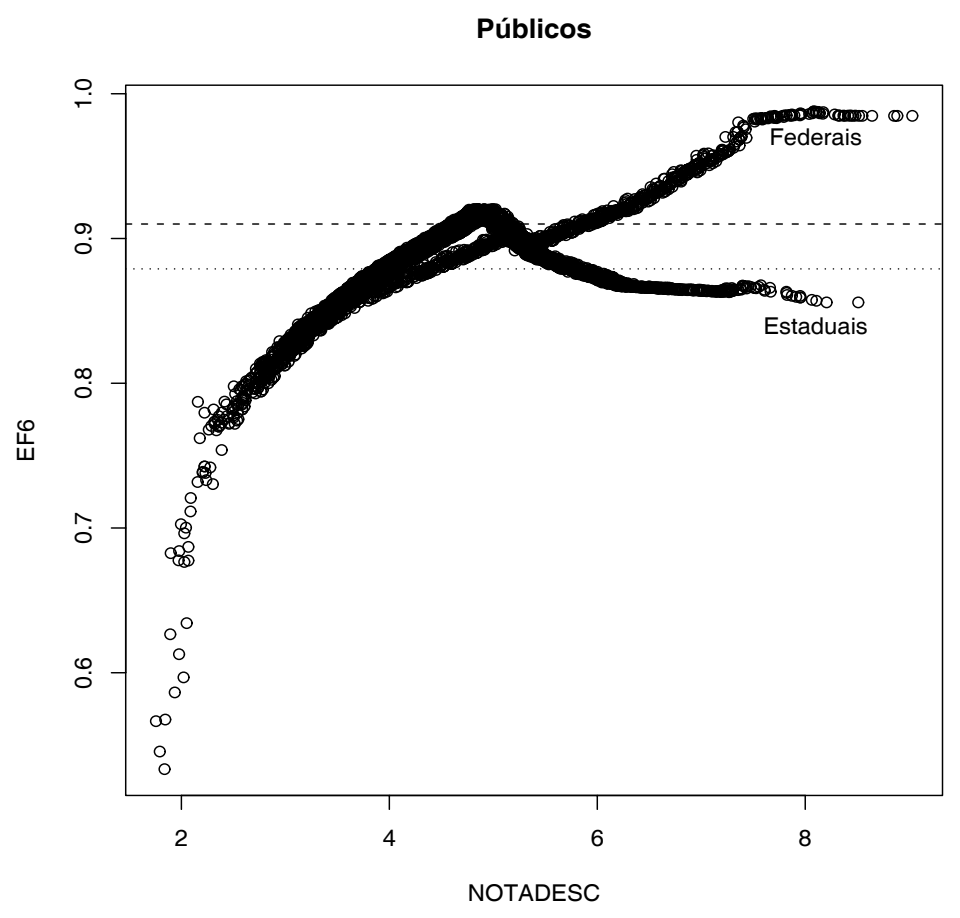

\section{CONCLUSÕES}

Analisar a eficiência dos estabelecimentos de ensino público e privado do Brasil, por meio da metodologia DEA, é de grande utilidade para que se tenha melhor conhecimento sobre quais fatores exercem maior influência na eficiência de um estabelecimento em relação a outro. Utilizou-se a metodologia desenvolvida por Thanassoulis (1999) e depois estendia por Portela e Thanassoulis (2001) para separar a eficiência geral em dois componentes: um componente atribuído à instituição de ensino que o estudante frequentou e outro componente atribuído à eficiência somente do estudante, ou seja, seu nível de esforço e motivação. Esta análise se mostra de grande importância, dado que pouco tem sido feito no Brasil a respeito de análise de eficiência de estabelecimentos de ensino básico e ainda utilizando-se dados não agregados.

Os resultados obtidos mostraram que, da amostra de colégios analisados, há uma grande disparidade entre os colégios privados e públicos. Os colégios privados obtiveram eficiência máxima, ou seja, a fronteira global é completamente determinada pela fronteira por tipo dos colégios privados. Isso mostra que nenhum colégio público conseguiu, em nenhum ponto da distribuição, atingir nível de eficiência global de 1. Com isso, a fronteira de eficiência por tipo dos colégios públicos ficou a uma distância média de eficiência de $10 \%$ em relação à fronteira 
global, obtendo coeficiente de eficiência médio de 0,901. Os colégios públicos foram então separados entre públicos estaduais e públicos federais. Os públicos federais apresentaram coeficiente de eficiência mais elevado que os públicos estaduais, sendo suas eficiências de 0,910 e 0,879, respectivamente.

Com relação à uniformidade do ensino, ou seja, que colégios mostraram-se igualmente eficientes para os diferentes níveis de aluno, destacaram-se os colégios privados com a menor dispersão, seguido dos colégios públicos federais e, por fim, dos públicos estaduais. Analisando diferenças de eficiência para diferentes níveis de entrada de aluno, mostrou-se que os colégios atendem de forma distinta a alunos com níveis de entrada diferentes. Ou seja, pode-se ter colégios com eficiências médias altas, mas que, para determinados alunos, apresentem eficiência bastante baixa.

Analisando os colégios públicos federais e estaduais quanto à eficiência para diferentes níveis de entrada de aluno, mostrou-se que, para alunos com nível de entrada abaixo da média, há pouca diferença entre os sistemas de ensino. No entanto, para alunos com nível de entrada superior à média, o sistema público federal mostrou-se bastante superior ao sistema público estadual, aproximando-se bastante do sistema de ensino privado para os melhores alunos. Isto mostra que, para os melhores alunos, estudar em escolas privadas ou públicas federais não é o decisivo para seu aprendizado. Para as escolas públicas estaduais, o impacto sobre o aprendizado dos melhores alunos é inferior à média geral dos colégios públicos estaduais.

Da análise, pode-se inferir a necessidade de substancial melhoria do ensino público, notadamente o estadual, para efetivamente contribuir para a redução das disparidades de oportunidade de ensino e, em última análise, para a redução das desigualdades sociais e econômicas.

\section{REFERÊNCIAS}

AMARAL, O. dos S. Avaliação da eficiência produtiva das unidades acadêmicas da Universidade do Amazonas, nos anos de 1994 e 1995, empregando Análise Envoltória de Dados. Dissertação (Mestrado) - Departamento de Engenharia de Produção e Sistemas, Universidade Federal de Santa Catarina, 1999.

ALBERNAZ, A., FERREIRA, F. H. G., FRANCO, C. Qualidade e equidade na educação fundamental brasileira. Departamento de Economia, PUC-Rio, 2002. 31 p. (Texto para Discussão, n. 455).

ARROW, K. J. The economic implications of learning by doing. Review of Economic Studies, 29, p. 155173, 1962.

BANKER, R. D.; CHARNES, A.; COOPER, W. W. Some models for estimating technical and scale inefficiencies. Management Science, v. 30, n. 9, p. 1078-1092, 1984.

BARBOSA, M. E.; FERNANDES, C. A escola brasileira faz diferença? Uma investigação dos efeitos da escola na proficiência em Matemática dos alunos da $4^{\mathrm{a}}$ série. In: FRANCO, C. (Org.). Promoção, ciclos e avaliação educacional. Curitiba: ArtMed, 2001.

BARROS, R. P. de; HENRIQUES, R.; MENDONÇA, R. Education and equitable economic development. Economia, v. 1, n. 1, p. 111-144, 2000. 
BASSETT, G.; TAM, M. S.; KNIGHT, K. Quantile models and estimators for Data Analysis. Metrika, v. 55, n. 1-2, p. 17-26, 2002.

BECKER, G.; MURPHY, K.; TAMURA, R. Human capital, fertility, and economic growth. Journal of Political Economy, 98, p. s12-s37, 1990.

BEE, M.; DOLTON, P. Degree class and pass rates: an inter-university comparison. Higher Education Review, 17, p. 45-52, 1985.

BELLONI, J. A. Uma metodologia de avaliação da eficiência produtiva de universidades federais brasileiras. Tese (Doutorado) - Departamento de Engenharia de Produção e Sistemas, Universidade Federal de Santa Catarina, 2000.

BENJAMIN, J.; OBENG, K. The effect of policy and background variables on total factor productivity for public transit. Transportation Research, v. 24, n. 1, p. 1-14, 1990.

BIRCH, E. R.; MILLER, P. W. Student outcomes at university in Australia: a quantile regression approach. Australian Economic Papers, v. 45, n. 1, 1-17, 2006.

CAVALCANTI, T., GUIMARÃES, J., SAMPAIO, B. Quantitative Evidences on Inequality of Opportunities in Brazil. Anais do XXIX Encontro Brasileiro de Econometria - SBE - Sociedade Brasileira de Econometria, Recife, 2007.

CHARNES, A.; COOPER, W.W.; RHODES, E. Measuring the efficiency of decision making units. European Journal of Operational Research, v. 2, n. 6, p. 429-444, 1978.

CLARK, E. E.; RAMSAY, W. Problems of retention in tertiary education. Education Research and Perspectives, 17, p. 47-57, 1990.

COOPER, W. W.; SEIFORD, L. M., TONE, K. Data envelopment analysis: a comprehensive text with models, applications, references and DEA solver software. Boston: Klumer Academic Publishers, 2000.

CURY, K. R. S. Análise Envoltória de dados aplicada à avaliação da pós-graduação das universidades federais. XXVII SBPO, Vitória, 1995.

FAÇANHA, L. O.; REZENDE, M.; MARINHO. A. Brazilian Federal Universities: relative evaluation and envelopment analysis. Rio de Janeiro: UFRJ, 1997.

GLASS, J. C.; MACKILLOP, D. G.; HYNDMAN, N. Efficiency in the prevision of university teaching and research: an empirical analysis of UK Universities. Journal of Applied Econometrics, v. 10, p. 61-72, 1995.

GOLDSTEIN, H. Methods in school effectiveness research. School Effectiveness and School Improvement, 8, p. 369-395, 1997.

GUIMARÃES, J. F., SAMPAIO, B. The influence of family background and individual characteristics on entrance tests scores of Brazilian university students. Anais do XXXV Encontro Nacional de Economia - ANPEC - Associação Nacional dos Centros de Pós-Graduação em Economia, Recife, 2007.

INEP - Instituto Nacional de Estudos e Pesquisas Educacionais Anísio Teixeira. PISA 2000. Relatório Nacional. 2001. Disponível em: <www.inep.gov.br>.

INEP - Instituto Nacional de Estudos e Pesquisas Educacionais Anísio Teixeira. Qualidade da Educação: Uma Nova Leitura do Desempenho dos Estudantes de $3^{\text {a }}$ Serie do Ensino Médio. 2004. Disponível em: www.inep.gov.br>. Acesso em: fev. 2007.

JESSON, D.; MAYSTON, D.; SMITH, P. Performance assessment in the education sector: educational and economic perspectives. Oxford Review of Education, 13, p. 249-266, 1987.

JOHNES, J. Measuring efficiency: a comparison of multilevel modeling and data envelopment analysis in the context of higher education. Bulletin of Economic Research, v. 58, n. 2, p. 75-104, 2006. 
JOHNES, G.; JOHNES, J. Measuring the research performance of uk economics departments: an application of data envelopment analysis. Oxford Economic Papers, 45, p. 332-347, 1993.

JOHNES, J.; TAYLOR, J.; FRANCIS, B. The research performance of UK universities: a statistical analysis of the results of the 1998 research selectivity exercise. Journal of the Royal Statistical Society, v. 156, n. 2, 271- 286, 1993.

LAPA, J. S.; LOPES, A. L. M.; LANZER, E. Análise Envoltória de Dados aplicada à avaliação de IES: determinação dos pesos relativos e valoração dos insumos e produtos. In: XXVII SBPO, Vitória, 1995.

LOPES, A. L. M.; LAPA, J. S.; LANZER, E. Eficiência produtiva em serviços governamentais: o caso da universidades federais brasileiras. In: FIRST INTERNATIONAL CONGRESS OF INDUSRIAL ENGENEERING; XV CONGRESSO NACIONAL DE ENGENHARIA DE PRODUÇÃO, São Carlos, 1995-a.

. Eficiência produtiva nas universidades federais: o quê indicam os indicadores do MEC? In: XX̄VII SBPO, Vitória, 1995-b.

. Análise Envoltória de dados: uma nova ferramenta para a avaliação multidimensional do setor de serviços. In: XX ENAMPAD, Angra dos Reis, 1996.

LUCAS, R. On the mechanics of economic development. Journal of Monetary Economics, 22, p. 3-42, 1988.

MA, L.; KOENKER, R. Quantile regression methods for recursive structural equation models. Journal of Econometrics, 134, p. 471-506, 2005.

MARINHO, A.; RESENDE, M.; FAÇANHA, L. O. Brazilian federal universities: relative efficiency evaluation and Data Envelopment Analysis. Revista Brasileira de Economia, 51, p. 489-508, 1997.

MCINNES, C.; JAMES, R.; MCNAUGHT, C. Diversity in the initial experiences of Australian undergraduates. Committee for the Advancement of University Teaching On-line. 1995. Available at: <www. online.anu.edu.au/caut/com... e/FYEfront.html.>

NUNES, N. Avaliação da eficiência produtiva de departamentos universitários: uma aplicação de Análise Envoltória de Dados. Dissertação (Mestrado) - UFSC, 1998.

PAIVA, F. C. Eficiência produtiva de programas de ensino de pós-graduação em engenharias: uma aplicação do Método Analise Envoltória de Dados - DEA. Dissertação (Mestrado) - Departamento de Engenharia de Produção, UFSC, 2000.

PAREDES, E. B. Análise de componentes principais e procedimento de Norman e Stoker: técnicas alternativas para identificação dos insumos e produtos relevantes no emprego da Análise Envoltória de Dados para avaliação da eficiência técnica de instituições federais de ensino superior. Dissertação (Mestrado) - Departamento de Engenharia de Produção e Sistemas, Universidade Federal de Santa Catarina, 1999.

PORTELA M. C.; THANASSOULIS, E. Decomposing school and school-type efficiency. European Journal of Operational Research, 132, p. 357-373, 2001.

POWER, C.; ROBERTSON, F.; BAKER, M. Success in higher education. Canberra: Australian Government Publishing Service, 1987.

RUHM, C. Is high school employment consumption or investment? Journal of Labor Economics, v. 15, n. 4, p. 735-776, 1997.

SMITH, J.; NAYLOR, R. Determinants of degree performance in UK universities: a statistical analysis of the 1993 student cohort. Oxford Bulletin of Economics and Statistics, v. 63, n. 1, 29-60, 2001.

STINEBRICKNER, R.; STINEBRICKNER, T. R. Working during school and academic performance. Journal of Labor Economics, v. 21, n. 2, p. 473-491, 2003. 
THANASSOULIS, E. Setting achievement targets for school children. Education Economics, v. 7, n. 2, p. 101-119, 1999.

TURNER, M. D. The Effects of Part-Time work on High School Students Academic Achievement. In: THE SOUTHERN ECONOMIC ASSOCIATION CONFERENCE, Orlando, FL, 1994.

UZAWA, H. Optimal technical change in an aggregative model of economic growth. International Economic Review, 6, p. 18-31, 1965.

WALTENBERG, F. D. Iniquidade educacional no Brasil. Uma avaliação com dados do PISA 2000. Economia, v. 6, n. 1, p. 67-118, 2005.

WIN, R.; MILLER, P. The effects of individual and school factors on university students academic performance. The Australian Economic Review, v. 38, n. 1, p. 1-18, 2005. 